\title{
DIGITAL PLATFORMIZATION IN THE CONTEXT OF INDUSTRY 4.0: THE UNCERTAINTY OF THE CONCEPTUAL FRAMEWORK ${ }^{1}$
}

\author{
Denis A. Appazov \\ Volgograd State University, Volgograd, Russian Federation \\ Yulia A. Tymchuk \\ Volgograd State University, Volgograd, Russian Federation
}

\begin{abstract}
Introduction: the paper analyzes the prospects for creating a regulatory framework for the digital platforms in Russia. The paper examines the existing approaches to the definition of "digital platform" in the legislation and legal doctrine, determines their role in the implementation of the state policy on building a digital economy, as well as the factors that led to their accelerated implementation in public administration. A critical analysis of the actions planned in the National plan that ensure the restoration of employment and income of the population, economic growth and long-term structural changes in the economy associated with digital platformization is carried out. The paper reveals the existing problems in the domestic law enforcement practice related to the functioning of the digital platforms in the context of legal uncertainty. The paper examines the foreign experience of the legislative regulation of digital platforms. Methods: in the study, the authors used both the general scientific methods (dialectical method of cognition, analysis, synthesis, formal logical method, prognostic method, etc.) and the specific scientific methods (formal legal method, method of legal interpretation, etc.). Results: the need to create a regulatory framework for the digital platforms in order to eliminate the identified problems of the law enforcement practice is justified. Conclusions: based on the results of the study and taking into account the analysis of the positive foreign experience, the authors' definition of the concept of digital (online) platform is formulated, and the main directions for improving the domestic legislation regulating the activities of the digital platforms in Russia are determined.
\end{abstract}

Key words: digital economy, COVID-19 pandemic, digital platform, digital technology (online) platform, aggregator of information about goods (services).

Citation. Appazov D.A., Tymchuk Yu.A. Digital Platformization in the Context of Industry 4.0: The Uncertainty of the Conceptual Framework. Legal Concept = Pravovaya paradigma, 2020, vol. 19, no. 4, pp. 33-42. (in Russian). DOI: https://doi.org/10.15688/lc.jvolsu.2020.4.4

\section{ЦИФРОВАЯ ПЛАТФОРМИЗАЦИЯ \\ В УСЛОВИЯХ ИНДУСТРИИ 4.0: НЕОПРЕДЕЛЕННОСТЬ ПОНЯТИЙНОГО АППАРАТА ${ }^{1}$}

\author{
Денис Альбертович Аппазов \\ Волгоградский государственный университет, г. Волгоград, Российская Федерация \\ Юлия Александровна Тымчук \\ Волгоградский государственный университет, г. Волгоград, Российская Федерация
}


Введение: в статье анализируются перспективы создания нормативного регулирования цифровых платформ в России. Рассматриваются существующие в законодательстве и юридической доктрине подходы к определению понятия «цифровая платформа», определяется их роль в реализации государственной политики по построению цифровой экономики, а также факторы, обусловившие их ускоренное внедрение в государственное управление. Проводится критический анализ запланированных в Общенациональном плане действий, обеспечивающих восстановление занятости и доходов населения, рост экономики и долгосрочные структурные изменения в экономике, связанных с цифровой платформизацией. Выявляются существующие в отечественной правоприменительной практике проблемы, связанные с функционированием цифровых платформ в условиях правовой неопределенности. Исследуется зарубежный опыт законодательного регулирования цифровых платформ. Методы: в настоящем исследовании были использованы как общенаучные (диалектический метод познания, анализ, синтез, формально-логический метод, прогностический и др.), так и частнонаучные методы (формально-юридический, метод юридического толкования и др.). Результаты: обоснована необходимость создания нормативных основ цифровых платформ в целях устранения выявленных проблем правоприменительной практики. Выводы: по итогам проведенного исследования и с учетом анализа положительного зарубежного опыта сформулировано авторское определение понятия «цифровая (онлайн) платформа», определены основные направления совершенствования отечественного законодательства, регламентирующего деятельность цифровых платформ в России.

Ключевые слова: цифровая экономика, пандемия COVID-19, цифровая платформа, цифровая технологическая (онлайн) платформа, агрегатор информации о товарах (услугах).

Цитирование. Аппазов Д. А., Тымчук Ю. А. Цифровая платформизация в условиях Индустрии 4.0: неопределенность понятийного аппарата // Legal Concept = Правовая парадигма. -2020 . - T. 19, № 4. - C. 33-42. DOI: https://doi.org/10.15688/lc.jvolsu.2020.4.4

\section{Введение}

В современных стремительно изменяющихся под влиянием различных объективных факторов условиях, связанных с динамичным развитием цифровых технологий, возникают новые формы общественных отношений, нуждающихся в надлежащем правовом обеспечении $[5$, с. $9 ; 29$, с. 3$]$.

По мнению авторов настоящей работы, сегодня к числу глобальных трендов цифрового развития следует отнести повсеместное внедрение в различные сферы общественной жизни цифровых технологических (онлайн) платформ [23, p. 27]. При этом фактором, усилившим данный тренд, выступает пандемия COVID-19, в условиях которой хозяйствующие субъекты, осознающие потребность в пересмотре традиционных подходов к ведению бизнеса, обратились к различным способам его цифровой трансформации, а именно внедрению платформенных бизнес-моделей, основанных на технологиях Индустрии 4.0 [7, с. 6]. С другой стороны, с точки зрения рядовых граждан, цифровые платформы выступают не только одним из способов удовлетворения различных бытовых потребностей, но и являются ключевым каналом для распространения информации, в том числе касающей- ся COVID-19. Последнее обстоятельство по данным Организации экономического сотрудничества и развития породило серьезную проблему, связанную с дезинформацией о COVID-19, размещаемой на цифровых платформах [18].

Онлайн-платформы в Европейском союзе признаются важной частью цифровой экономики и цифрового европейского общества.

Зарубежные специалисты обращают внимание на то, что «цифровая платформа обеспечивает непрерывный бизнес-процесс, необходимый для улучшения взаимодействия с клиентами, сотрудниками и партнерами» [26].

В ежегодном рейтинге Doing Business, опубликованном Всемирным банком, также указывается, что экономики государств, набравших наибольшие баллы, обладают рядом особенностей, включая широкое использование электронных систем и онлайн-платформ, имеющих нормативные основы [22].

Востребованность для экономического роста и развития нашего государства цифровых платформ отмечается и на государственном уровне. В частности, в одном из своих обращений Президент РФ В.В. Путин подчеркнул, что «цифровые платформы кардинально повышают открытость и эффективность работы органов власти, компаний, бизнеса, социальных и образовательных учреждений» [2]. 
Большой массив возникающих в рамках цифровых платформ общественных отношений, заключаемых посредством них сделок между субъектами гражданского оборота, в том числе международного, объективно порождают вопрос об их правовом урегулировании [24, с. 421$]$.

\section{Вектор на создание нормативных основ для цифровой платформизации государственного управления и предпринимательской деятельности}

Несмотря на высокую оценку возможностей цифровых платформ для ведения бизнеса $[6$, с. 8] и осуществления государственного управления, единообразного определения понятия «цифровая платформа» или «цифровая технологическая (онлайн) платформа» не сложилось ни в юридической науке, ни в законодательстве.

Вместе с тем возможно утверждать, что о некоторых их разновидностях имеется упоминание в нормативно-правовых актах, принятых на федеральном уровне. Так, в частности, речь идет о Законе РФ от 07.02.1992 № 2300-1 «О защите прав потребителей», в котором содержится определение понятия «владелец агрегатора информации о товарах (услугах)» [21, с. 27].

Кроме того, ряд ключевых инициатив в сфере государственного управления в настоящее время также базируется на цифровых платформенных решениях. Например, в Общенациональном плане действий, обеспечивающих восстановление занятости и доходов населения, рост экономики и долгосрочные структурные изменения в экономике [11], запланировано создание единой цифровой платформы (Государство как цифровая платформа для комплексного оказания государственных услуг в цифровом виде, комфортной работы и развития субъектов МСП, социальной поддержки населения с акцентом на адресность мер поддержки и пр.). Бесспорно, реализация обозначенного мероприятия положительно отразится на динамике развития цифровой экономики нашего государства, однако по смыслу программы создания комплексной нормативной основы для процессов цифровой платформизации не запланировано (в разделе «Регуляторное обеспечение внедрения цифровых технологий» предусмотрены лишь точечные меры, например, определение антимонопольных требований к деятельности цифровых платформ и пр.). Данное обстоятельство, по мнению авторов, свидетельствует о том, что до настоящего времени рассматриваемая проблема не решена на законодательном уровне.

Определение понятия «цифровая платформа» возможно обнаружить в решении Высшего Евразийского экономического совета [15], в котором она рассматривается как система средств, поддерживающая использование цифровых процессов, ресурсов и сервисов значительным количеством субъектов цифровой экосистемы и обеспечивающая возможность их бесшовного взаимодействия. С одной стороны, подобный широкий подход к определению рассматриваемого понятия выглядит оправданным, однако, с другой стороны, в вышеприведенном определении обозначены далеко не все ключевые сущностные признаки цифровых платформ (например, снижение транзакционных издержек, алгоритмизация и пр.).

В юридической доктрине также существуют некоторые отдельные теоретические разработки по рассматриваемой проблематике, однако ее комплексного монографического исследования не проводилось.

Так, представители юридической науки предлагают понимать под цифровыми технологическими (онлайн) платформами «комплекс технологических решений в цифровом пространстве сети Интернет на основе сочетания программных алгоритмов (компьютерных кодов), компьютерного технологического оборудования, «облачных» вычислений, больших баз данных, а также других цифровых технологий (блокчейн-технологии, аналитика данных, искусственный интеллект и т. д.)» [8, с. 25].

В научном сообществе справедливо обращают внимание на то обстоятельство, что цифровые платформы остаются практически не затронутыми юридическими правилами [9, c. 31]. С данным утверждением сложно не согласиться.

Между тем стремительное увеличение масштабов использования физическими и юридическими лицами цифровых платформ в совокупности с объективной потребностью в 
нормативном урегулировании возникающих правоотношений позволяет исследователям использовать категорию «платформенное право» [1, с. 245].

Существует и немногочисленная судебная практика по спорам с хозяйствующими субъектами, так называемыми платформенными компаниями. В числе ключевых проблем правоприменительной практики, которые в настоящее время решаются усилиями судебных органов: проблема имущественной ответственности платформенных компаний [10, с. 149] и проблема правового статуса лиц, работающих в цифровых компаниях [16, с. 18].

Так, например, в одном из дел по иску физического лица к цифровой платформе (ООО «Яндекс.Такси») о возмещении вреда, причиненного здоровью в результате ДТП, компенсации морального вреда суд с учетом позиции, изложенной в п. 18 Постановления Пленума Верховного Суда РФ от 26.06.2018 № 26, отверг доводы платформенной компании о том, что организация не является перевозчиком, фрахтовщиком или диспетчерской службой, не является исполнителем услуги по отношению к истцу и т. Д., поскольку платформенная компания в отношениях с истцом действовала исключительно от своего имени [3]. Следует отметить, что подобной позиции цифровая платформа придерживается и в ряде других споров [12-14].

В другом деле истец обратился в суд с иском к платформенной компании $(\mathrm{OOO}$ «Яндекс.Такси») об установлении факта трудовых отношений, обязании заключить трудовой договор. По мнению истца, который являлся водителем в ООО «Яндекс.Такси», между ним и платформенной компанией фактически сложились трудовые правоотношения. Между тем данная позиция была признана ошибочной, поскольку из представленных в материалы дела документов не усматривалось наличие существенных условий, характеризующих трудовые отношения. В удовлетворении иска было отказано, апелляционная инстанция оставила решение суда первой инстанции без изменения [4].

Кроме того, отдельной серьезной проблемой, нуждающейся в нормативном регулировании, является и налогообложение цифровых компаний.

\section{Европейский опыт}

законодательного регулирования цифровых платформ

Поскольку в настоящее время, исходя из анализа отечественного законодательства, цифровые платформы функционируют в условиях правовой неопределенности, что собственно влияет как на осуществление хозяйственной деятельности, так и на возможные риски, с которыми могут столкнуться как потребители услуг платформенных компаний, так и третьи лица, чьи права потенциально могут быть нарушены, обратимся к анализу положительного европейского опыта нормативного регулирования цифровых платформ.

В Европе формирование основ правового регулирования цифровых платформ началось в 2016 году.

В мае 2016 г. Европейской комиссией была проведена комплексная оценка онлайнплатформ, результатом которой стало несколько документов.

Так, был опубликован рабочий документ Комиссии по онлайн-платформам, который представляет собой обзор основных характеристик онлайн-платформ, в том числе наиболее популярных бизнес-моделей с использованием онлайн-платформ, и их социально-экономического вклада в Европе. Несмотря на то что данный документ не имеет нормативного характера, он представляет особую ценность, поскольку в нем детально описаны, в том числе с учетом проведенных консультаций с общественностью, концептуальные моменты, касающиеся сущности, особенностей функционирования и роли отдельных видов цифровых платформ, используемых в предпринимательской деятельности [19].

Вторым документом, который также был опубликован по итогам работы Комиссии, стал Отчет «Исследование о перспективах экономической политики в отношении онлайнплатформ», подготовленный Бертином Мартенсом. В отчете исследователь рассмотрел в том числе возможные регуляторные меры в области конкуренции, защиты прав потребителей и персональных данных, принятие которых целесообразно в связи с функционированием онлайн-платформ [25]. 
На момент проведения описываемой аналитической работы нормативное определение онлайн-платформ только формировалось. Вместе с тем проведенные социологические опросы позволили выявить положительное отношение к онлайн-платформам большинства респондентов, которые обращали внимание на преимущества данных цифровых инструментов [28].

В итоговом документе, разработанном по результатам проведенной работы, были сформулированы принципы, которыми рекомендовано руководствоваться при создании нормативного регулирования онлайн-платформ, среди которых такие, как: равные условия для сопоставимых цифровых услуг; ответственное поведение онлайн-платформ для защиты основных ценностей; прозрачность и справедливость для поддержания доверия пользователей и защиты инноваций; открытые и недискриминационные рынки в экономике, основанной на данных [20].

Представители европейского научного сообщества также приняли участие в разработке рассматриваемого вопроса. Так, группой зарубежных исследователей был опубликован проект Директивы об онлайн-посреднических платформах, известный также как Академический проект [17].

С точки зрения проблематики настоящего исследования интерес представляет анализ такого документа, как Регламент (ЕC) 2019/1150 Европейского парламента и Совета от 20 июня 2019 г. «О продвижении справедливости и прозрачности для бизнес-пользователей онлайн-посреднических услуг» (далее Регламент) [27]. В Регламенте особо подчеркивается, что посреднические онлайн-услуги могут сыграть ключевую роль в деле достижения коммерческого успеха организации. Представляется, что такая позиция, особенно с учетом непредсказуемой эпидемиологической обстановки на фоне COVID-19, выглядит как никогда актуально. Вместе с тем для полного использования всех преимуществ ведения бизнеса посредством онлайн-платформ важно доверие к таким компаниям как со стороны контрагентов, так и со стороны потребителей, поскольку с ростом влияния таких компаний на рынке существуют вполне реальные риски, связанные с недобросовестным поведением онлайн-платформ во взаимоотношениях с контрагентами, навязыванием невыгодных условий заключаемых договоров, несправедливой практики и пр.

Одним из преимуществ указанного Регламента, на наш взгляд, выступает максимальный учет сущностных признаков цифровых платформ и тенденций их развития. В частности, общеизвестно, что цифровые платформы в настоящее время имеют глобальный характер. Данное обстоятельство учтено в Регламенте. Так, сфера действия Регламента распространяется на онлайн-платформы независимо от того, созданы ли они в каком-либо государстве-члене или за пределами Европейского союза. Регламентом также закрепляются основные понятия, требования к поставщикам услуг онлайн-посредничества, к информации о товарах и услугах, предоставляемых посредством онлайн-платформы, правила о разрешении споров, положения об органах, уполномоченных на обращение с исками в случае несоблюдения обязанными субъектами правил Регламента и пр.

Представляется, что закрепленные в Регламенте правила отвечают критериям универсальности и могут быть восприняты отечественным законодателем.

\section{Выводы}

Таким образом, проведенное исследование позволяет прийти к следующим выводам.

Цифровые платформы, являющиеся важной частью экосистемы цифровой экономики, возможно считать эффективным инструментом организации бизнеса, а также процессов государственного управления.

Возникающие в связи с функционированием цифровых платформ отношения нуждаются в надлежащем правовом обеспечении, которое в настоящее время фактически отсутствует.

При этом представляется, что первоочередной мерой в подобных условиях является теоретико-правовое осмысление категории «цифровая (онлайн) платформа». С учетом имеющихся в настоящее время доктринальных и нормативных разработок цифровую (онлайн) платформу возможно определить как интегрированную многофункциональную ин- 
формационную систему в сети Интернет, основанную на сквозных и других цифровых технологиях, обеспечивающих процессы алгоритмизированного прямого взаимодействия, в том числе осуществления трансакций, между платформенными акторами, а также реализацию бизнес-процессов с наименьшими трансакционными, временными и иными издержками. На наш взгляд, наличие признака прямого взаимодействия платформенных акторов в рамках конкретной цифровой платформы также позволяет утверждать о целесообразности расширения теории организационных правоотношений в гражданском праве.

Регулирование общественных отношений, в которые вступают заинтересованные субъекты, обращаясь за оказанием услуг или приобретением товаров к цифровой платформе (цифровая платформа как бизнес-модель), осуществляется на уровне самих цифровых платформ (в пользовательских соглашениях, правилах оказания услуг и пр.). Восполнение имеющихся законодательных пробелов осуществляется на уровне правоприменителей, что не является нормальным явлением для страны, правовая система которой относится к романо-германской. Такая ситуация с учетом наличия потенциальных рисков нарушения прав как контрагентов цифровых платформ, так и рядовых потребителей недопустима.

Вместе с тем авторы не являются сторонниками позиции по «заурегулированию» рассматриваемых отношений. Представляется, что правовое регулирование столь специфических правоотношений в цифровой среде должно базироваться на принципах гибкости и динамичности.

В связи с этим представляется, что возможно воспринять положительный зарубежный опыт по организации работы по созданию нормативной базы для цифровых платформ. В подобной работе необходим комплексный подход, который не может ограничиваться разработкой и принятием отдельных законов, регулирующих ту или иную сферу деятельности цифровых платформ (например, антимонопольное законодательство и пр.). В частности, прежде всего, следует провести качественный и количественный анализ рынка цифровых платформ, функционирующих на территории России, ус- тановить на нормативном уровне критерии отнесения компаний к цифровым, а также требования к содержанию локальных нормативных актов таких организаций, сведений, которые в обязательном порядке должны быть доступны для неопределенного круга лиц, в том числе потребителей товаров (услуг), рассмотреть возможность разработки специального налогового режима для цифровых платформ. Отдельного внимания также заслуживает вопрос об определении правового статуса лиц, задействованных в работе цифровых платформ, что обосновывается потребностью в минимизации нарушений прав таких лиц и в перспективе количества трудовых споров, рассматриваемых в судебном порядке.

После реализации обозначенного мероприятия, а также с учетом имеющегося технического уровня развития цифровых (онлайн) платформ возможно рассмотреть вопрос о подготовке законопроекта о внесении изменений в часть первую Гражданского кодекса РФ, в гл. 4 «Юридические лица», в которой закрепить новую статью, определяющую понятие цифровой (онлайн) платформы.

Кроме того, представляется, что реформирование данного сектора цифровой экономики должно производиться поэтапно в целях предотвращения возникновения дополнительных расходов и убытков у цифровых компаний и недопущения отказа компаний от цифровой трансформации организации на фоне искусственно созданных нормативных барьеров для входа на рынок.

\section{ПРИМЕЧАНИЕ}

1 Работа выполнена при поддержке Российского научного фонда (проект № 20-18-00314).

The work was supported by Russian Science Foundation (project no. 20-18-00314).

\section{СПИСОК ЛИТЕРАТУРЫ}

1. Алтухов, А. В. Платформенное право как механизм юридического регулирования цифровых платформ умных городов / А. В. Алтухов // Цивилизационная роль права в современных интеграционных процессах : науч.-практ. конф. - М., 2020. C. $245-250$. 
2. АНО «Цифровые платформы». - Электрон. текстовые дан. - Режим доступа: https:/diplatforms.ru/ (дата обращения: 10.10.2020). - Загл. с экрана.

3. Информация по делу № 33-415164/2020. Решение Первомайского районного суда города Москвы от 24.07.2020 г. по делу № 2-706/20 // Официальный портал судов общей юрисдикции города Москвы. - Электрон. текстовые дан. - Режим доступа: https:/ /www.mos-gorsud.ru/mgs/services/cases/appeal-civil/ details/66986c90-2006-11eb-8922-91f0d74f320e (дата обращения: 20.10.2020). - Загл. с экрана.

4. Информация по делу № 33-53437/2019. Апелляционное определение Судебной коллегии по гражданским делам Московского городского суда от 22.11.2020 по делу № 33-53437/2019 // Официальный портал судов общей юрисдикции города Москвы. Электрон. текстовые дан. - Режим доступа: https:// www.mos-gorsud.ru/mgs/services/cases/appeal-civil/ details/3a706793-408c-4059-9c94-8bdcc1 f8dea7 (дата обращения: 20.10.2020). - Загл. с экрана.

5. Иншакова, А. О. Реакция права на вызовы высоких технологий в инновационной России / А. О. Иншакова // Legal Concept = Правовая парадигма. - 2018. - T. 17, № 4. - C. 6-15. - DOI: https:// doi.org/10.15688/lc.jvolsu.2018.4.1.

6. Иншакова, А. О. Право как основа инфраструктурного обеспечения цифровой экономики и технологии Интернета вещей / А. О. Иншакова // Legal Concept = Правовая парадигма. -2019 . T. 18, № 3. - C. 6-11. - DOI: https://doi.org/10.15688/ lc.jvolsu.2019.3.1.

7. Иншакова, А. О. Право и информационно-технологические преобразования общественных отношений в условиях Индустрии 4.0 / А. О. Иншакова // Legal Concept $=$ Правовая парадигма. -2019 . - Т. 18, № 4. C. 6-17.-DOI:https://doi.org/10.15688/lc.jvolsu.2019.4.1.

8. Карцхия, А. А. Цифровые технологические (онлайн) платформы: российский и зарубежный опыт регулирования / А. А. Карцхия // Гражданское право. - 2019. - № 3. - С. 25-28.

9. Кашкин, С. Ю. В поисках концепции правового регулирования искусственного интеллекта: платформенные правовые модели / С. Ю. Кашкин, А. В. Алтухов // Вестник Университета им. О.Е. Кутафина. - 2020. - № 4 (68). - С. 26-40.

10. Лютов, Н. Л. Водители такси, выполняющие работу через онлайн-платформы: каковы правовые последствия «уберизации» труда? / Н. Л. Лютов, И. В. Войтковская // Актуальные проблемы российского права. - 2020. - № 6. - С. 149-159.

11. Общенациональный план действий, обеспечивающих восстановление занятости и доходов населения, рост экономики и долгосрочные структурные изменения в экономике (одобрен на заседании Правительства РФ 23 сентября 2020 г. (протокол № 36, раздел VII) № П13-60855 от 2 октября
2020 г.). - Доступ из справ.-правовой системы «Гарант.ру».

12. Решение Арбитражного суда Кемеровской области от 22.06.2020 по делу № А27-4842/2019 // Картотека арбитражных дел. - Электрон. текстовые дан. - Режим доступа: https://ras.arbitr.ru/Document/ Pdf/2b858598-1d69-4407-acd1-6f5d13c2389b/e3f2c5b88d48-4759-8ad9-54410c5bf8e6/\%D0\%9027-48422019 20200622.pdf?isAddStamp=True (дата обращения: 23.10.2020). - Загл. с экрана.

13. Решение Арбитражного суда Кемеровской области по делу № А27-4822/2020 от 23.12.2019 // Картотека арбитражных дел. - Электрон. текстовые дан. - Режим доступа: https://ras.arbitr.ru/ Document/Pdf/e309ee34-d876-4f94-9267-10894d09c601/ f3816c4a-4723-42be-aea0-80888fab2c24/\%D0\%90274822-2019_20191223.pdf?isAddStamp=True (дата обращения: 23.10.2020). - Загл. с экрана.

14. Решение Арбитражного суда Ульяновской области от 22.01.2020 по делу № A72-13761/2019// Картотека арбитражных дел. - Электрон. текстовые дан. - Режим доступа: https://ras.arbitr.ru/Document/Pdf/ 7ebfd3b4-8599-4f25-8639-3c61005716fd/3334530d1b3d-43dd-aab5-856dc478dd3b/\%D0\%9072-137612019 20200122.pdf?isAddStamp=True (дата обращения: 23.10.2020). - Загл. с экрана.

15. Решение Высшего Евразийского экономического совета от 11.10.2017 № 12 «Об основных направлениях реализации цифровой повестки Евразийского экономического союза до 2025 года» // Правовой портал Евразийского экономического союза. - Электрон. текстовые дан. - Режим доступа: https://docs.eaeunion.org/docs/ru-ru/01415213/ scd_10112017_12 (дата обращения: 12.10.2020). Загл. с экрана.

16. Шуралева, С. В. Работники в «облаках»: влияние интернет-платформ на развитие трудовых отношений / С. В. Шуралева // Трудовое право в России и за рубежом. -2019 . - № 1. - С. 15-18.

17. Christoph Busch, Gerhard Dannemann, Hans Schulte-Nölke, Aneta Wiewiyrowska, Fryderyk Zoll Discussion Draft of a Directive on Online Intermediary Platforms. - Electronic text data. - Mode of access: https://www.researchgate.net/publication/ 308522861_Discussion_Draft_of_a_Directive_on Online_Intermediary_Platforms (date of access: 30.10.2020). - Title from screen.

18. Combatting COVID-19 disinformation on online platforms // Organisation for Economic. Cooperation and Development. - Electronic text data. - Mode of access: http://www.oecd.org/coronavirus/policy-responses/ combatting-covid-19-disinformation-on-onlineplatforms-d854ec48/ (date of access: 15.10.2020). - Title from screen.

19. Commission Staff Working Document on Online Platforms, accompanying the document 
«Communication on Online Platforms and the Digital Single Market» (COM(2016) 288)// European Commission. - Electronic text data. - Mode of access: https://ec.europa.eu/digital-single-market/en/news/ commission-staff-working-document-online-platforms (date of access: 25.10.2020). - Title from screen.

20. Communication from the commission to the European parliament, the Council, the European economic and social committee and the committee of the regions Online Platforms and the Digital Single Market Opportunities and Challenges for Europe COM/ 2016/0288 final // EUR-LEX. - Electronic text data. Mode of access: http://eur-lex.europa.eu/legalcontent/EN/TXT/?uri=CELEX:52016DC0288 (date of access: 26.10 .2020$)$. - Title from screen.

21. Deryugina, T. V. Systemic issues of legal regulation for information aggregator operation / T. V. Deryugina, A. O. Inshakova, M. V. Sevostyanov // Studies in Computational Intelligence. - 2019. Vol. 826.- P. 27-34.

22. Doing Business 2020. Comparing Business Regulation in 190Economies// Doingbusiness. Measuring Business Regulations. - Electronic text data. - Mode of access: https://openknowledge. worldbank.org/bitstream/ handle/10986/32436/9781464814402.pdf(date of access: 11.10.2020). - Title from screen.

23. Inshakova, E. I. Russian and Eurasian Technology Platforms: Progress and Challenges in Accelerating the Neo-Industrialization Processes / E. I. Inshakova, R. M. Kachalov, A. O. Inshakova // Competitive Russia: Foresight Model of Economic and Legal Development in the Digital Age. CRFMELD 2019. Lecture Notes in Networks and Systems / ed. by A. Inshakova, E. Inshakova. 2020. - Vol. 110. Springer, Cham. - P. 27-34.

24. Inshakova, A. O. Civil law in the digital economy: Analysis of doctrinal adaptation trends / A. O. Inshakova, E. I. Inshakova, A. J. Ryzhenkov, M. V. Sevostyanov // Lecture Notes in Networks and Systems. - 2020. - Vol. 110. - P. 421-429.

25. Martens Bertin An Economic Policy Perspective on Online Platforms //EUSCIENCE HUB. - Electronic text data. - Mode of access: https://ec.europa.eu/jrc/en/ publication/eur-scientific-and-technical-research-reports/ economic-policy-perspective-online-platforms?search (date of access: 25.10.2020). - Title from screen.

26. Peter Bendor-Samuel What is a digital platform? // The Enterprisers Project. - Electronic text data. - Mode of access: https://enterprisersproject. com/article/2018/12/what-digital-platform (date of access: 11.10 .2020$)$. - Title from screen.

27. Regulation (EU) $2019 / 1150$ of the European Parliament and of the Council of 20 June 2019 on promoting fairness and transparency for business users of online intermediation services (Text with EEA relevance) // Eur-Lex. - Electronic text data. - Mode of access: https://eur-lex.europa.eu/legal-content/EN/ $\mathrm{TXT} /$ ?uri=CELEX\%3A32019R1150\&qid $=16050027$ 62270 (date of access: 25.10.2020). - Title from screen.

28. Synopsis report on the public consultation on the regulatory environment for platforms, online intermediaries and the collaborative economy// European Commission. - Electronic text data. - Mode of access: https://ec.europa.eu/digital-single-market/en/news/fullreport-results-public-consultation-regulatoryenvironment-platforms-online-intermediaries (date of access: 27.10.2020). - Title from screen.

29. Tarakanov, V. V. Information society, digital economy and law / V. V. Tarakanov, A. O. Inshakova, V. V. Dolinskaya // Studies in Computational Intelligence. -2019. - Vol. 826. - P. 3-15.

\section{REFERENCES}

1. Altukhov A.V. Platformennoe pravo kak mekhanizm yuridicheskogo regulirovaniya cifrovyh platform umnyh gorodov [Platform Law as a Mechanism for Legal Regulation of Digital Platforms of Smart Cities]. Civilizacionnaya rol' prava $v$ sovremennyh integracionnyh processah: nauch.-prakt. konf. [Scientific and Practical Conference. The Civilizational Role of Law in Modern Integration Processes]. Moscow, Moscow Publ., 2020, pp. 245-250.

2. ANO «Cifrovye platformy» [ANO "Digital Platforms"]. URL: https://diplatforms.ru/ (accessed 27 October 2020).

3. Informaciya po delu № 33-415164/2020. Reshenie Pervomajskogo rajonnogo suda goroda Moskvy ot 24.07.2020 po delu № 2-706/20 [Information on case No. 33-415164/2020. Decision of the Pervomaisky District Court of Moscow of 24.07.2020 in case No. 2-706/20]. Oficial'nyj portal sudov obshchej yurisdikcii goroda Moskvy [Official Portal of Courts of General Jurisdiction of Moscow]. URL: https://www.mos-gorsud.ru/mgs/services/cases/ appeal-civil/details/66986c90-2006-11eb-892291f0d74f320e (accessed 20 October 2020).

4. Informaciya po delu № 33-53437/2019. Apellyacionnoe opredelenie Sudebnoj kollegii po grazhdanskim delam Moskovskogo gorodskogo suda ot 22.11.2020 po delu №33-53437/2019 [Information on case No. 33-53437/2019. Appellate Determination of the Judicial Board for Civil Cases of the Moscow City Court from 22.11.2020 in case No. 33-53437/2019]. Oficial'nyj portal sudov obshchej yurisdikcii goroda Moskvy [Official Portal of the Courts of General Jurisdiction of the City of Moscow]. URL: https://www.mos-gorsud.ru/ mgs/services/cases/appeal-civil/details/3a706793-408c4059-9c94-8bdcc1f8dea7 (accessed 20 October 2020).

5. Inshakova A.O. Reakciya prava na vyzovy vysokih tekhnologij v innovacionnoj Rossii [The 
Response of Law to the Challenges of High Technologies in Innovative Russia]. Legal Concept = Pravovaya paradigma, 2018, no. 4 (17), pp. 6-15. DOI: https://doi.org/10.15688/lc.jvolsu.2018.4.1.

6. Inshakova A.O. Pravo kak osnova infrastrukturnogo obespecheniya cifrovoj ekonomiki i tekhnologii Interneta veshchej [Law as the Basis of Infrastructure Support of the Digital Economy and Technology of the Internet of Things]. Legal Concept $=$ Pravovaya paradigma, 2019, no. 3 (18), pp. 6-11. DOI: https://doi.org/10.15688/lc.jvolsu.2019.3.1.

7. Inshakova A.O. Pravo i informacionnotekhnologicheskie preobrazovaniya obshchestvennyh otnoshenij $\mathrm{v}$ usloviyah industrii 4.0 [Law and Information Technology Transformations of Public Relations in Industry 4.0]. Legal Concept $=$ Pravovaya paradigma, 2019, no. 4 (18), pp. 6-17. DOI: https://doi.org/10.15688/lc.jvolsu.2019.4.1.

8. Kartskhia A.A. Cifrovye tekhnologicheskie (onlajn) platformy: rossijskij i zarubezhnyj opyt regulirovaniya [Digital Technological (Online) Platforms: Russian and Foreign Regulatory Experience]. Grazhdanskoe pravo [Civil Law], 2019, no. 3, pp. 25-28.

9. Kashkin S.Y., Altuhov A.V. V poiskah koncepcii pravovogo regulirovaniya iskusstvennogo intellekta: platformennye pravovye modeli [In Search of the Concept ofLegal Regulation of Artificial Intelligence: Platform Legal Models]. Vestnik Universiteta im. O.E. Kutafina [Bulletin of the O.E. Kutafin University], 2020, no. 4(68), pp. 26-40.

10. Lyutov N.L., Vojtkovskaya I.V. Voditeli taksi, vypolnyayushchie rabotu cherez onlajn-platformy: kakovy pravovye posledstviya «uberizacii» truda? [Taxi Drivers Performing Work Through Online Platforms: What are the Legal Consequences of "Uberization" of Labor?]. Aktual'nye problemy rossijskogo prava [Current Problems of Russian Law], 2020, no. 6, pp. 149-159.

11. Obshchenacional'nyj plan dejstvij, obespechivayushchih vosstanovlenie zanyatosti $i$ dohodov naseleniya, rost ekonomiki i dolgosrochnye strukturnye izmeneniya $v$ ekonomike (odobren na zasedanii Pravitel'stva RF 23 sentyabrya $2020 \mathrm{~g}$. (protokol № 36, razdel VII) № P13-60855 ot 2 oktyabrya 2020 g.) [A Nationwide Action Plan Ensuring the Restoration of Employment and Incomes of the Population, Economic Growth and Long-Term Structural Changes in the Economy (Approved at a Meeting of the Government of the Russian Federation on September 23, 2020 (Protocol No. 36, Section VII) No. П13-60855 of October 2, 2020]. Access from Reference Legal System "Garant".

12. Reshenie Arbitrazhnogo suda Kemerovskoj oblasti ot 22.06.2020 po delu № A27-4842/2019 [Decision of the Arbitration Court of the Kemerovo Region from 22.06.2020 in the case of A27-4842/2019]. Kartoteka arbitrazhnyh del [File Cabinet of Arbitration Cases]. URL: https://ras.arbitr.ru/Document/Pdf/2b858598-1d69- 4407-acd1-6f5d13 c2389b/e3f2c5b8-8d48-4759-8ad954410 c5bf8e6/\%D0\%9027-4842-2019 20200622. pdf?isAddStamp=True (accessed 20 October 2020).

13. Reshenie Arbitrazhnogo suda Kemerovskoy oblasti po delu № A27-4822/2020 ot 23.12.2019 [Decision of the Arbitration Court of the Kemerovo Region in Case no. A27-4822/2020 dated 23.12.2019]. Kartoteka arbitrazhnyh del [File Cabinet of Arbitration Cases]. URL: https://ras.arbitr.ru/ Document/Pdf/e309ee34-d876-4f94-9267-10894d09 c601/f3816c4a-4723-42be-aea0-80888fab2c24/ \%D0\%9027-4822-2019_20191223.pdf?isAdd Stamp $=$ True (accessed 20 October 2020).

14. Reshenie Arbitrazhnogo suda Ul'yanovskoy oblasti ot 22.01.2020 po delu №A72-13761/2019 [Decision of the Arbitration Court of the Ulyanovsk Region from 22.01.2020 in Case no. A72-13761/2019]. Kartoteka arbitrazhnyh del [File Cabinet of Arbitration Cases]. URL: https://ras.arbitr.ru/Document/Pdf/7ebfd3b4-8599-4f258639-3c61005716fd /3334530d-1b3d-43dd-aab5856dc478dd3b/\%D0\%9072-13761-2019_20200122.pdf ?isAddStamp $=$ True (accessed 23 October 2020).

15. Reshenie Vysshego Evrazijskogo ekonomicheskogo soveta ot 11.10.2017 g. №12 «Ob osnovnyh napravleniyah realizacii cifrovoj povestki Evrazijskogo ekonomicheskogo soyuza do 2025 goda» [Decision of the Supreme Eurasian Economic Council of 11.10.2017 No. 12 "On the Main Directions for the Implementation of the Digital Agenda of the Eurasian Economic Union Until 2025"]. Pravovoj portal Evrazijskogo ekonomicheskogo soyuza [Legal Portal of the Eurasian Economic Union]. URL: https://docs.eaeunion.org/docs/ru-ru/01415213/ scd_10112017_12 (accessed 12 October 2020).

16. Shuraleva S.V. Rabotniki v «oblakah»: vliyanie internet-platform na razvitie trudovyh otnoshenij [Workers in the "Clouds": The Influence of Internet Platforms on the Development of Labor Relations]. Trudovoe pravo $v$ Rossii $i$ za rubezhom [Labor Law in Russia and Abroad], 2019, no. 1, pp. 15-18.

17. Christoph Busch, Gerhard Dannemann, Hans Schulte-Nölke, Aneta Wiewiyrowska, Fryderyk Zoll Discussion Draft of a Directive on Online Intermediary Platforms. URL: https://www. researchgate.net/publication/308522861_Discussion Draft_of_a_Directive_on_Online_Intermediary_Platforms (accessed 30 October 2020).

18. Combatting COVID-19 Disinformation on Online Platforms. Organisation for Economic. Cooperation and Development. URL: http:// www.oecd.org/coronavirus/policy-responses/ combatting-covid-19-disinformation-on-onlineplatforms-d854ec48/ (accessed 15 October 2020).

19. Commission Staff Working Document on Online Platforms, Accompanying the Document "Communication on Online Platforms and the Digital 
Single Market” (COM(2016) 288). European Commission. URL: https:/ec.europa.eu/digital-singlemarket/en/news/commission-staff-working-documentonline-platforms (accessed 25 October 2020).

20. Communication from the Commission to the European Parliament, the Council, the European Economic and Social Committee and the Committee of the Regions Online Platforms and the Digital Single Market Opportunities and Challenges for Europe COM/ 2016/0288 final. EUR-LEX. URL: http://eur-lex. europa.eu/legal-content/EN/TXT/?uri=CELEX: 52016DC0288 (accessed 26 October 2020).

21. Deryugina T.V., Inshakova A.O., Sevostyanov M.V. Systemic Issues of Legal Regulation for Information Aggregator Operation. Studies in Computational Intelligence, 2019, no. 826, pp. 27-34.

22. Doing Business 2020. Comparing Business Regulation in 190 Economies. Doingbusiness. Measuring Business Regulations. URL: https://openknowledge. worldbank.org/bitstream/handle/10986/32436/ 9781464814402.pdf(accessed 11 October 2020).

23. Inshakova E.I., Kachalov R.M., Inshakova A.O. Russian and Eurasian Technology Platforms: Progress and Challenges in Accelerating the NeoIndustrialization Processes. Inshakova A., Inshakova E., eds. Competitive Russia: Foresight Model of Economic and Legal Development in the Digital Age. CRFMELD 2019. Lecture Notes in Networks and Systems, 2020, vol. 110. Springer, Cham, pp. 27-34.
24. Inshakova A.O., Inshakova E.I., Ryzhenkov A.J., Sevostyanov M.V. Civil law in the Digital Economy: Analysis of Doctrinal Adaptation Trends. Lecture Notes in Networks and Systems, 2020, no. 110, pp. 421-429.

25. Martens Bertin An Economic Policy Perspective on Online Platforms. EU SCIENCE HUB. URL: https:// ec.europa.eu/jrc/en/publication/eur-scientific-andtechnical-research-reports/economic-policy-perspectiveonline-platforms?search (accessed 25 October 2020).

26. Peter Bendor-Samuel What is a Digital Platform? The Enterprisers Project. URL: https:// enterprisersproject.com/article/2018/12/what-digitalplatform (accessed 11 October 2020).

27. Regulation (EU) $2019 / 1150$ of the European Parliament and of the Council of 20 June 2019 on promoting fairness and transparency for business users of online intermediation services (Text with EEA relevance). Eur-Lex. URL: https://eur-lex.europa.eu/ legal-content/EN/TXT/?uri=CELEX\%3A32019 R1 150\&qid $=1605002762270$ (accessed 25 October 2020).

28. Synopsis report on the public consultation on the regulatory environment for platforms, online intermediaries and the collaborative economy. European Commission. URL: https:/ec.europa.eu/ digital-single-market/en/news/full-report-results-publicconsultation-regulatory-environment-platforms-onlineintermediaries (accessed 27 October 2020).

29. Tarakanov V.V., Inshakova A.O., Dolinskaya V.V. Information Society, Digital Economy and Law. Studies in Computational Intelligence, 2019, no. 826, pp. 3-15.

\section{Information About the Authors}

Denis A. Appazov, Laboratory Assistant, Department of Civil and Private International Law, Base Department of the Southern Scientific Centre of the Russian Academy of Sciences, Volgograd State University, Prosp. Universitetsky, 100, 400062 Volgograd, Russian Federation, gimchp@volsu.ru, https://orcid.org/0000-0003-1063-4202

Yulia A. Tymchuk, Researcher, Department of Civil and Private International Law, Base Department of the Southern Scientific Centre of the Russian Academy of Sciences, Volgograd State University, Prosp. Universitetsky, 100, 400062 Volgograd, Russian Federation, tymchuk@volsu.ru, yuliannatymchuk@yandex.ru, https://orcid.org/0000-0002-0854-3179

\section{Информация об авторах}

Денис Альбертович Аппазов, лаборант кафедры гражданского и международного частного права (базовая кафедра ЮНЦ РАН), Волгоградский государственный университет, просп. Университетский, 100, 400062 г. Волгоград, Российская Федерация, gimchp@volsu.ru, https://orcid.org/0000-0003-1063-4202

Юлия Александровна Тымчук, научный сотрудник кафедры гражданского и международного частного права (базовая кафедра ЮНЦ РАН), Волгоградский государственный университет, просп. Университетский, 100, 400062 г. Волгоград, Российская Федерация, tymchuk@volsu.ru, yuliannatymchuk@yandex.ru, https://orcid.org/0000-0002-0854-3179 